\title{
An experimental study on the safe placement of sacroiliac screws using a 3D printing navigation module
}

\author{
Xuanhuang Chen ${ }^{1,2 \#}$, Feng Zheng ${ }^{1 \#}$, Guodong Zhang ${ }^{1 \#}$, Xiaoqiang Gao ${ }^{1}$, Ya Wang ${ }^{3}$, Wenhua Huang ${ }^{3}$, \\ Haibin Lin ${ }^{1,2}$ \\ ${ }^{1}$ Department of Orthopedics, the Affiliated Hospital of Putian University, Putian, China; ${ }^{2}$ The Third School of Clinical Medicine, Southern Medical \\ University, Guangzhou, China; ${ }^{3}$ National Key Discipline of Human Anatomy, School of Basic Medical Science, Southern Medical University, \\ Guangzhou, China \\ Contributions: (I) Conception and design: X Chen, H Lin; (II) Administrative support: H Lin; (III) Provision of study materials or patients: X Gao, \\ Y Wang, W Huang; (IV) Collection and assembly of data: X Chen, F Zheng, G Zhang; (V) Data analysis and interpretation: X Chen, H Lin; (VI) \\ Manuscript writing: All authors; (VII) Final approval of manuscript: All authors. \\ "These authors contributed equally to this work as co-first authors. \\ Correspondence to: Haibin Lin. Department of Orthopedics, the Affiliated Hospital of Putian University, No. 999 Dongzhen Dong Road, Licheng \\ District, Putian, China. Email: ptyygklhb@126.com; Wenhua Huang. National Key Discipline of Human Anatomy, School of Basic Medical \\ Sciences, Southern Medical University, No. 1838 Guangzhou Road North, Guangzhou, China. Email: 578818837@qq.com.
}

Background: In this experimental study, we evaluated the use of digital 3D navigation printing in minimizing complications arising from sacroiliac screw misplacement.

Methods: A total of 13 adult pelvic specimens were studied using 3D navigation printing. Mimics software was used for preoperative planning and for obtaining sacrum median sagittal resection and long axis resection of the $\mathrm{S} 1$ pedicle center by 3D segmentation. The ideal screw path had its origin at the post-median part of the auricular surface of the sacroiliac joint, the midpoint at the mid-position of the lateral recess and outlet of the anterior sacral foramina; and the endpoint at the S1 sagittal resection. A sacroiliac screw fixed the pelvic specimens with the assistance of the navigation module. The distance between the start point (ilium surface) and endpoint (sacral median sagittal resection) of the screw path was measured after the pre- and postoperative $3 \mathrm{D}$ pelvis module was $3 \mathrm{D}$-registered according to the standard precision range. The origin/endpoint qualified rates of the postoperative $(\mathrm{n} / 26)$ and preoperative (26/26) screw paths were analyzed by the chi-square test.

Results: No screw misplacement occurred in the screw paths of any of the 13 pelvic specimens. The mean distance between the preoperative and postoperative origin of the screw path was $1.5415 \pm 0.6806 \mathrm{~mm}$, and the mean distance between the preoperative and postoperative endpoint was $2.2809 \pm 0.4855 \mathrm{~mm}$. The qualified rate of origin was $23 / 26$ when the precision grade was $2.4 \mathrm{~mm}\left(\mathrm{P}>0.05, \chi^{2}=1.41\right)$, while the qualified rate of endpoint was $21 / 26$ when the precision grade was $2.7 \mathrm{~mm}\left(\mathrm{P}>0.05, \chi^{2}=3.54\right)$.

Conclusions: In this experimental study, using a $3 \mathrm{D}$ printing navigation module helped attain an accurate and safe sacroiliac screw implantation.

Keywords: Sacroiliac screw; internal fixation; digitization; 3D printing navigation; computer-assisted

Submitted Sep 21, 2020. Accepted for publication Nov 12, 2020.

doi: $10.21037 / \mathrm{atm}-20-7080$

View this article at: http://dx.doi.org/10.21037/atm-20-7080

\section{Introduction}

Unstable posterior pelvic ring injuries (UPPRI) usually result from violent high-impact injuries (1-3). They are associated with high morbidity and mortality due to iatrogenic injury to anatomically contiguous structures and the prolonged patient immobilization that is often required in the event of complications $(4,5)$. The posterior pelvic ring bears approximately $70 \%$ of the pelvic weight. Therefore, 
good treatment efficacy is a key surgical imperative that can help minimize complications and the duration of immobilization. Conservative treatment outcomes have been largely disappointing1, and are often associated with long-term sequelae such as chronic pain and an inability to walk normally $(2,3)$.

The posterior pelvic ring needs to be efficiently repaired in order to maintain the stability of the pelvis (6). Matta et al. were the first to report the use of the sacroiliac screw for the internal fixation of UPPRI (7). This innovation overcame many of the limitations of the traditional techniques, including the risk of neurovascular injury resulting from the use of the anterior plate and sacral bar fixations (7). The use of one or more sacroiliac screws helps to attain the internal fixation of UPPRI with minimal trauma to soft tissues (8-13). However, sacroiliac screw implantation is a challenging procedure with a high risk of complications due to the potential for misplacement and the proximity to vital anatomical structures like the cauda equina, sacral nerves, internal and external iliac vessels, as well as the limited visual access of the surgical field (14-17). Computer navigation (15) and 2D-fluoroscopic navigation (18) are more recent techniques for guiding screw implantation, but they have had mixed results. Previous studies have shown that the preoperative design of sacroiliac screw path is based on the fixed entry point and stop point, and the established screw path is fixed, which can not guarantee that the design results of each patient's screw path are safe. To overcome the limitations of these methods, we experimented with a novel technique based on thin-slice CT scan data to guide sacroiliac screw placement using a $3 \mathrm{D}$ printing navigation module. Our objective was to evaluate the efficacy of this novel technique in lowering the risk of screw misplacement.

We present the following article in accordance with the MDAR reporting checklist (available at http://dx.doi. org/10.21037/atm-20-7080).

\section{Methods}

\section{Samples and experimental materials}

All procedures performed in this study involving human participants were in accordance with the Declaration of Helsinki (as revised in 2013). The Institutional Review Board at the Affiliated Hospital of Putian University approved this study (batch number: 20140012). Written informed consent was obtained from all patients. A total of 13 adult cadaveric pelvic specimens were used (10 females,
3 males). The software packages included Mimics 14.0 (Department of Human Anatomy of Southern Medical University School of Basic Medicine) and Makerware (freeware). Other equipment included Dell T7500 graphics workstation, Makerbot Replicator 2 3D printer (USA), and SIEMENS/Emotion 16 volumetric CT (Department of Image, Affiliated Hospital, Putian University). The following orthopedic instruments were used: Kirschner wire ( $\Phi 2.5 \mathrm{~mm})$, hollow drill ( $\Phi 5.0 \mathrm{~mm})$, hollow tap $(\Phi 5.0 \mathrm{~mm})$, and industrial stainless steel sink-screws of various sizes (Ф6.5, 35-80 mm, $5 \mathrm{~mm}$ stepping).

\section{Thin slice CT scan and $3 D$ reconstruction}

All pelvic specimens were scanned using the following parameters: voltage $130 \mathrm{KV}$, electricity $21.6 \mathrm{~mA}$, reconstruction interval $0.625 \mathrm{~mm}$, and pixels $512 \times 512$. A standard algorithm was used to produce and transmit the image to a personal graphics workstation in Digital Imaging and Communications in Medicine (DICOM) format through Picture Archiving and Communication Systems (PACS). Mimics was preset at a threshold value of 120-Maximum Hu. We used region-growing and morphology operations, including the number of pixels (2), operation at the close, and 8-connectivity to perform the $3 \mathrm{D}$ reconstruction after transmission of the DICOM files to Mimics.

\section{Sacroiliac screw path arrangement}

The menu operation was preset to "Cut Orthogonal to Screen". The pelvis was segmented anterior to the sacroiliac joint to reserve the sacrum and posterior part of the ilium (Figure 1A). The posterior pelvic ring was then segmented into two separate sacroiliac joints along the sacrum median sagittal resection, removing the anterior pelvic ring (Figure 1B). The $\mathrm{S} 1$ pedicle was regulated to its smallest view and segmented along the long axis of the $\mathrm{S} 1$ pedicle center to obtain a paralleled resection, which was at least $5 \mathrm{~mm}$ from the upper endplate of S1 (Figure 1C).

We determined the sacroiliac screw path $(\Phi 7.3 \mathrm{~mm}$, length $150 \mathrm{~mm}$ ) at the two separate pedicle resections from the inside out using the menu operation of MedCAD/ Create Cylinder (Figure 1D). The ideal origin of the screw path was at the post-median part of the auricular surface through the junction of the sacrum and ilium. The ideal endpoint was at the midpoint of the S1 sagittal resection. The screw path needed to pass through the midpoint of the 

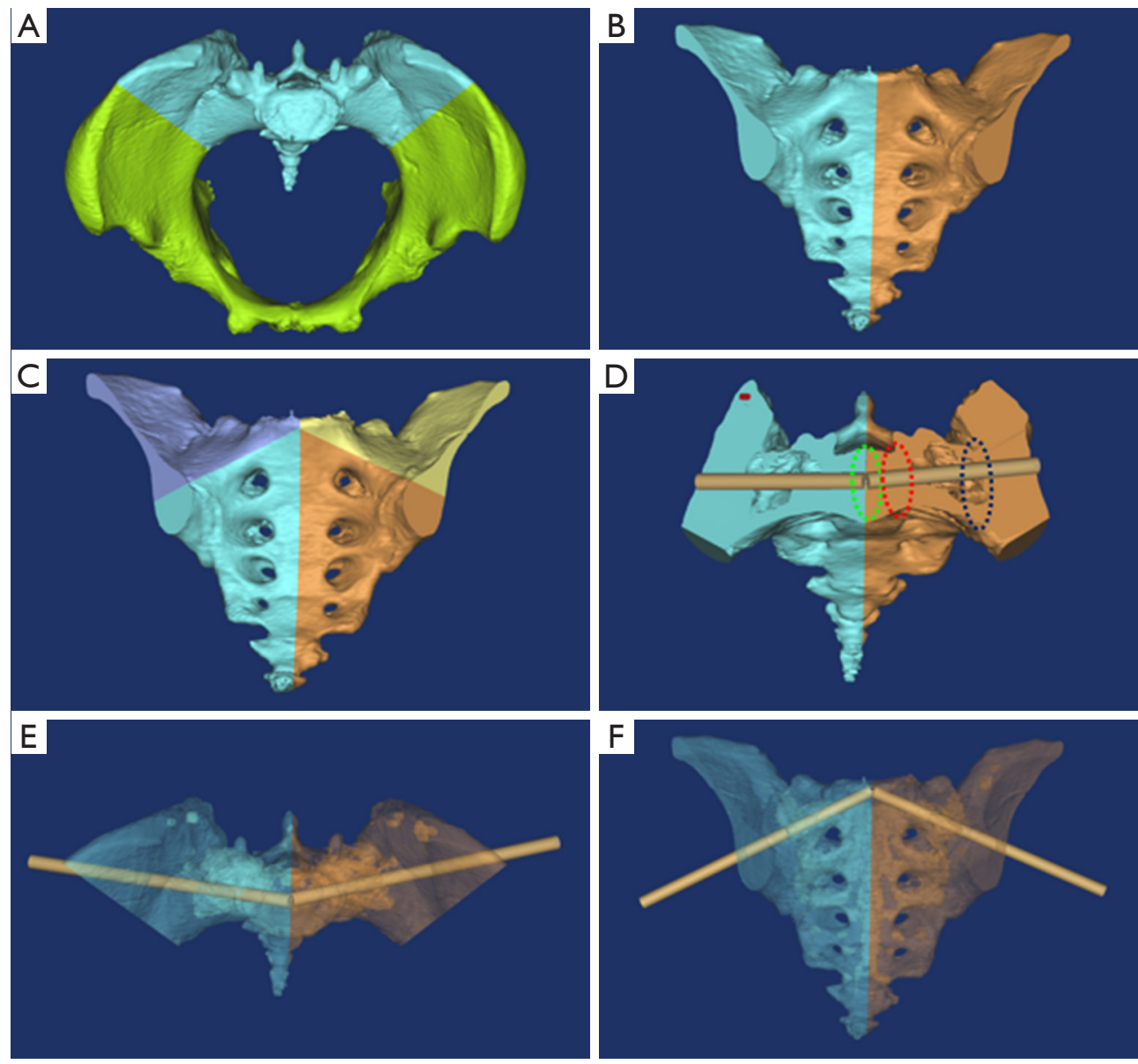

Figure 1 Screw path arrangement. (A) Reserved posterior ring after segmentation; (B) sacrum median sagittal resection; (C) two separate S1 pedicle resections; (D) screw path arrangement; (E,F) the effect of the screw channel.

lateral recess and the outlet of the anterior sacral foramina. Based on the above criteria, we designed a $3 \mathrm{D}$ printing navigation module (Figure 1E,F).

\section{The design and print of the navigation module}

The various components of the design process are outlined below: (I) to design the supporting pillar of the navigation module, the screw path was replicated and enlarged to $\Phi 10 \mathrm{~mm}$. The length was regulated approximately $35 \mathrm{~mm}$ from the iliac surface in the menu operation of MedCAD/ Cylinder. (II) The design of the socket module consisted of the following steps: "Simulation/Cut Orthogonal to Screen" was applied in the menu operation; the posterior part of the ilium was precisely segmented to include bony components such as the iliac posterior gluteal line posterior to the bone surface for ease of operation (Figure $2 A$ ); a socket module approximately $4-6 \mathrm{~mm}$ in thickness was obtained in simulation/reposition; the screw path was replicated and narrowed to $\Phi 2.8 \mathrm{~mm}$ in order to fit the $\Phi 2.5 \mathrm{~mm}$ Kirschner wire; the navigation module was obtained using the following Boolean operators: [(socket module + supporting pillar) - (screw path + pelvic)] (Figure 2B,C); the navigation module had a concave structure which we entitled "locating surface fitting with the bone process of the posterior gluteal line", and with all other parts entitled "stable surface" (Figure 2D). (III) The navigation modules data was transmitted to Makeware as an STL file to perform high precision printing.

\section{Surgical procedure}

The incision was made from the posterior superior iliac spine commencing in a forward direction $5 \mathrm{~cm}$ along the iliac crest and then turning externally for $5 \mathrm{~cm}$ towards the femoral greater tuberosity (Figure $3 A, B$ ). The gluteus 

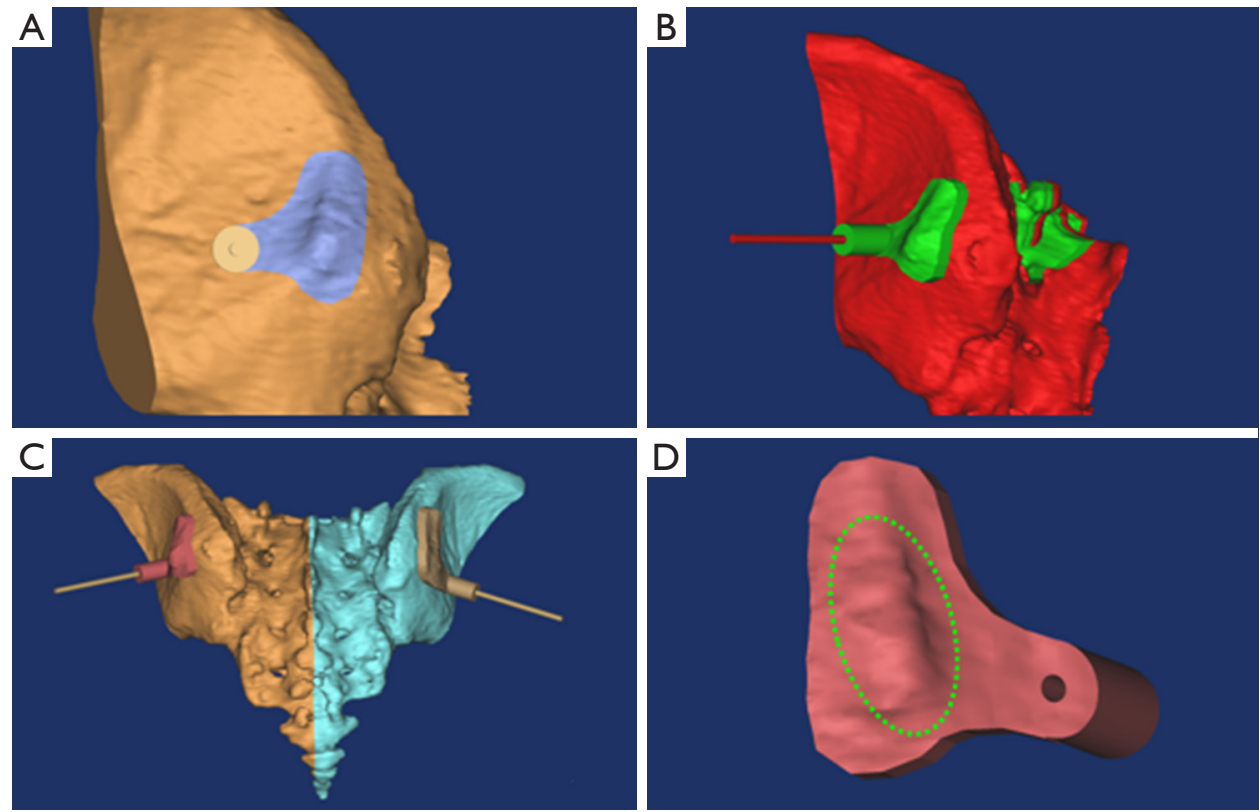

Figure 2 The design of the navigation module. (A) Bone surface segmentation; (B) Boolean operation after draft; (C) navigation modules; (D) the position surface of the navigation module.
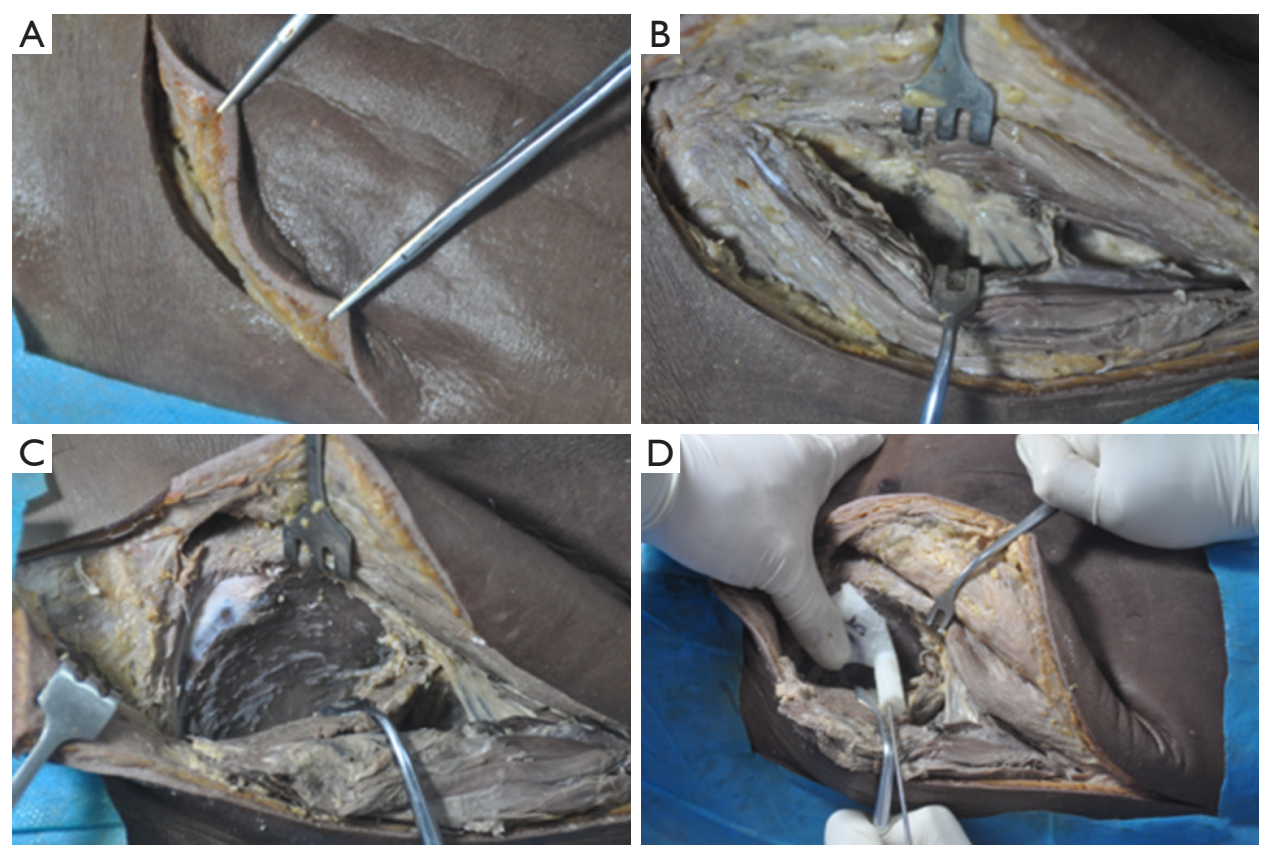

Figure 3 The surgical procedure with the navigation module. (A) Surgical incision; (B) stepwise blunt separation of gluteus medius and maximus; (C) periosteal stripping; (D) navigation module position.

medius was exposed via blunt dissection and the gluteus maximus while protecting the superior gluteal vessels. The gluteus medius was then separated with blunt dissection via a periosteal elevator at the lateral surface of the ilium, and the gluteus maximus and iliac crest were separated at their attachment point by sharp dissection (Figure 3C). The sole qualified position was the "gold standard" for the navigation module, insofar as the navigation module was a perfect fit 

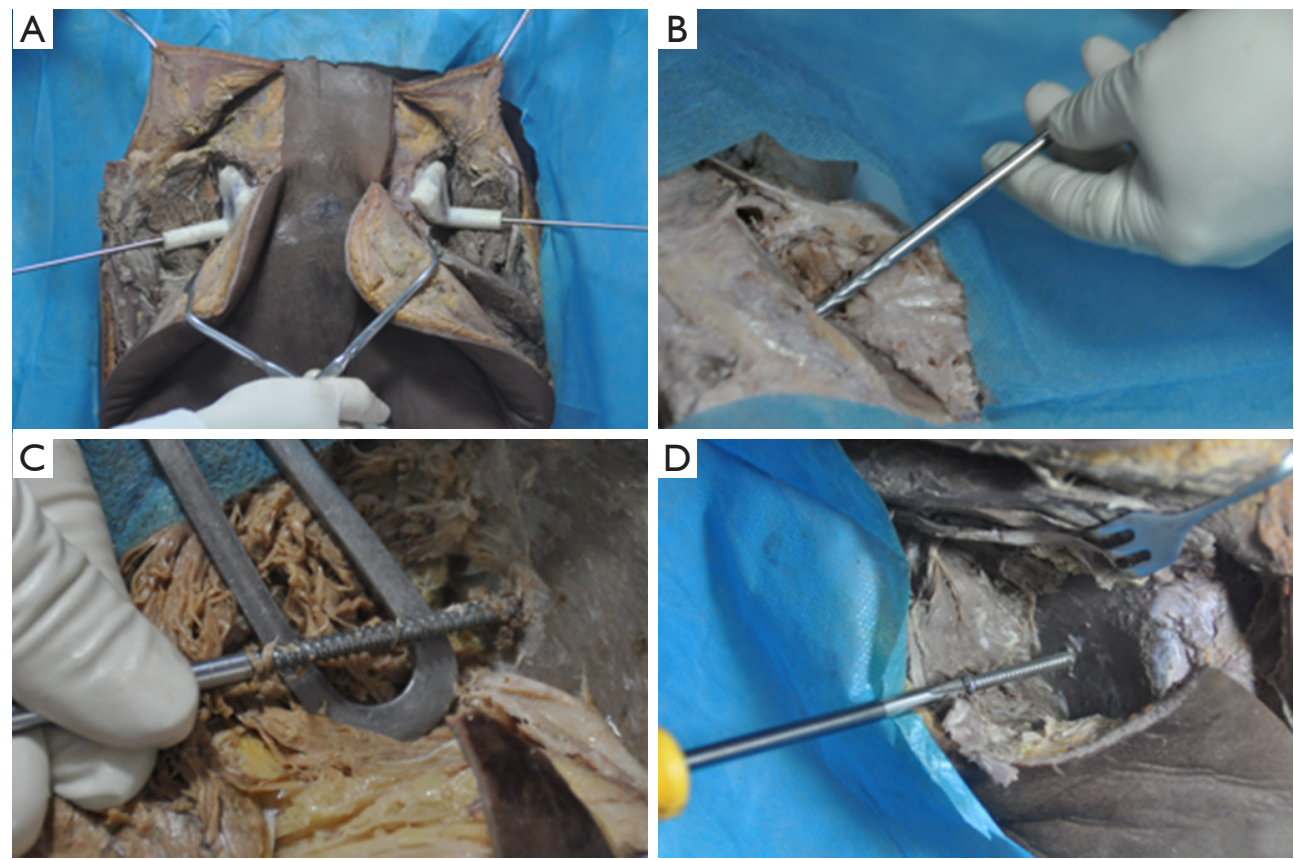

Figure 4 Thoracic pedicle screw placement assisted with the navigation module. (A) Symmetrical screw path; (B) drilling bone cortex with the hollow drill; (C) reaming with the hollow tap; (D) screw placement.

with the bone surface. Moreover, there was no rotation or slide between the navigation module and the bone surface, even when pressure was applied to the navigation module (Figure 3D). A Kirschner wire was inserted from the supporting pillar of the navigation module to check the symmetry of the right and left Kirschner wires (Figure 4A). A hollow drill was used to drill the bone cortex along the Kirschner wire after removing the navigation module. A safe screw path was obtained by reaming with the hollow tap (Figure $4 B, C)$, and then an industrial screw $(\Phi 6.5 \mathrm{~mm})$ was inserted along the screw path (Figure $4 D$ ).

\section{Postoperative $3 D$ registration and effect observation of screw placement}

Thin slice CT scan and 3D reconstruction of postoperative specimens were performed (Figure $5 A$ ). The merged 3D module of the postoperative pelvis and screws (simulation/ merge) was transmitted to the preoperative designed mask as an STL format file, which was primarily matched with the designed 3D module with the "registration/point registration" command. Automatic registration was achieved with the "registration/global registration" order (Figure 5B).

The postoperative module was divided into bone and screws with the "simulation/split" order, and the postoperative screw path was reconstructed along the long axis of the screw with MedCAD/Cylinder (Figure 5C). The position of the postoperative screw path and its relationship with the adjacent structures was observed (Figure 5D,E). The pre- and post-operative distances between the origin (ilium surface) and endpoint (sacral median sagittal resection) of the screw path were measured after setting the diameter of the screw path at $0.1 \mathrm{~mm}$ (Figure $5 F$ ), which was the precision standard.

\section{Statistical analysis}

The SPSS software version 19.0 was used for analyses. Starting from $1 \mathrm{~mm}$, the origin/endpoint qualified rate of the postoperative (n/26) and preoperative (26/26) screw paths were analyzed by the chi-square test with the stepping of $0.1 \mathrm{~mm}$.

\section{Results}

All 26 sacroiliac screws used in the study were implanted successfully with no incidence of malpositioning. The effect of sacroiliac screw placement is shown in Figure 6. The mean distance between the preoperative and postoperative origin of the screw path was $1.5415 \pm 0.6806 \mathrm{~mm}$, while the 

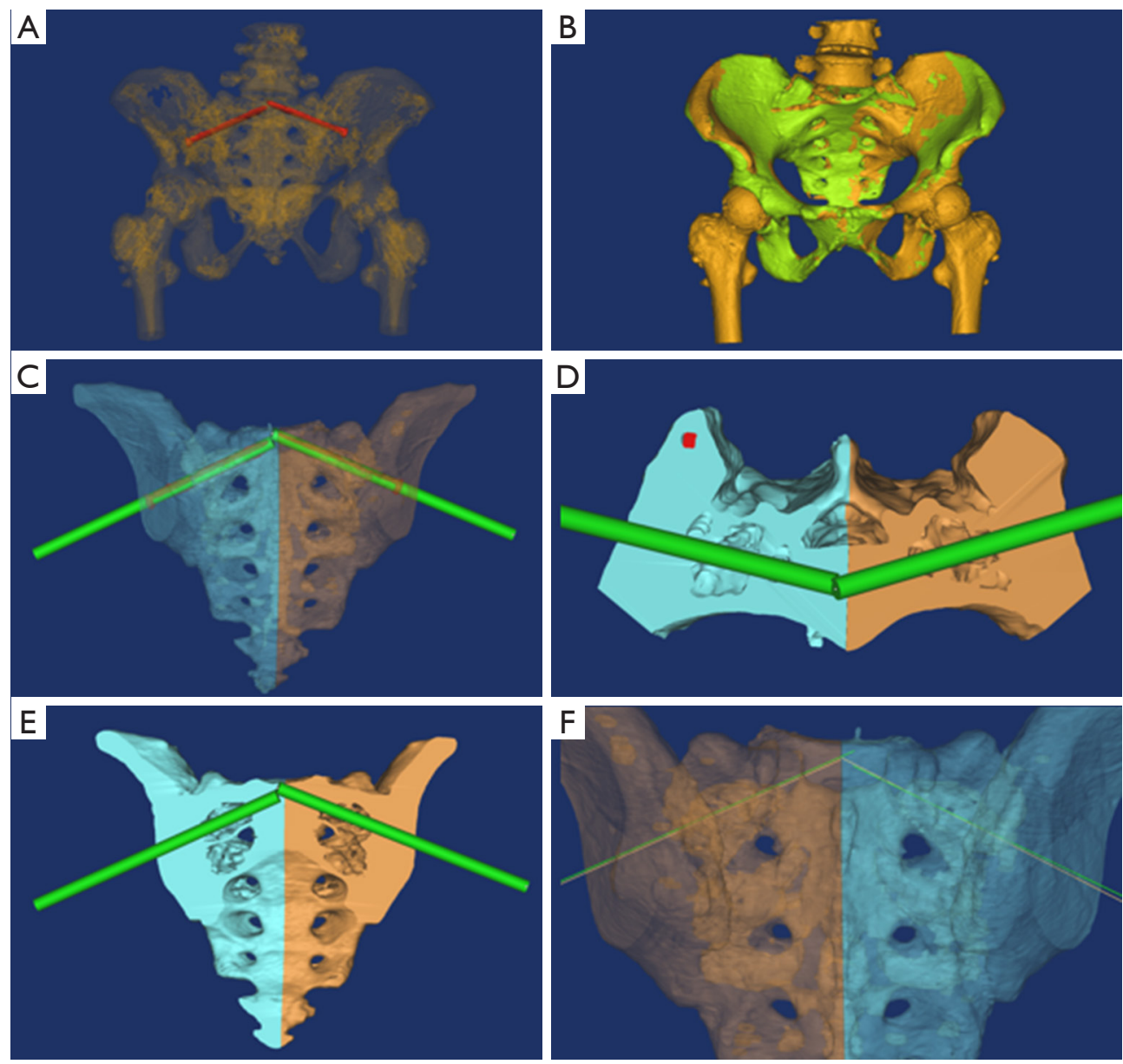

Figure 5 3D matching and the effect of screw placement. (A) Postoperative pelvis and screws; (B) 3D matching; (C) reconstructed screw path; $(\mathrm{D}, \mathrm{E})$ postoperative position of the screw path; $(\mathrm{F})$ precision of origin and endpoint.

mean distance between the preoperative and postoperative endpoints of the screw path was $2.2809 \pm 0.4855 \mathrm{~mm}$. The qualified rate of origin was $23 / 26$ when the precision grade was $2.4 \mathrm{~mm}\left(\mathrm{P}>0.05, \chi^{2}=1.41\right)$, while the qualified rate of origin was $20 / 26$ when the precision grade was $2.3 \mathrm{~mm}$ $\left(\mathrm{P}<0.05, \chi^{2}=4.71\right)$. For the endpoint, the qualified rate was $21 / 26$ when the precision grade was $2.7 \mathrm{~mm}(\mathrm{P}>0.05$, $\chi^{2}=3.54$ ), while the qualified rate was $20 / 26$ when the precision grade was $2.6 \mathrm{~mm}\left(\mathrm{P}<0.05, \chi^{2}=4.71\right)$.

\section{Discussion}

The advantages of using sacroiliac screws for fixation of UPPRI include good biomechanical stability, short operative time, and rapid functional rehabilitation of the patient (19-22). However, the risk of screw misplacement and radiation exposure remain key limitations (23-25). In this study, we employed a novel technique by designing a 3D navigation module for preoperative digital planning of the screw path. This approach allowed for sacroiliac screw placement based on applied anatomy knowledge and a 3D navigation module. All (26) sacroiliac screws were appropriately placed in the 13 pelvic specimens used in this study. The qualified rate of origin was completely successful when the precision grade of origin was $2.4 \mathrm{~mm}$, and the endpoint was $2.7 \mathrm{~mm}$.

Optimal placement of a sacroiliac screw requires familiarity with sacroiliac joint anatomy and depends on meticulous preoperative planning and good visibility (26). Inter-individual variations in the sacral morphology and the degree of fracture displacement make the procedure challenging (27). The narrow sacral proportions and double cone-shaped screw path places the adjacent neurovascular structures at risk of iatrogenic injury (28). Therefore, pre- 

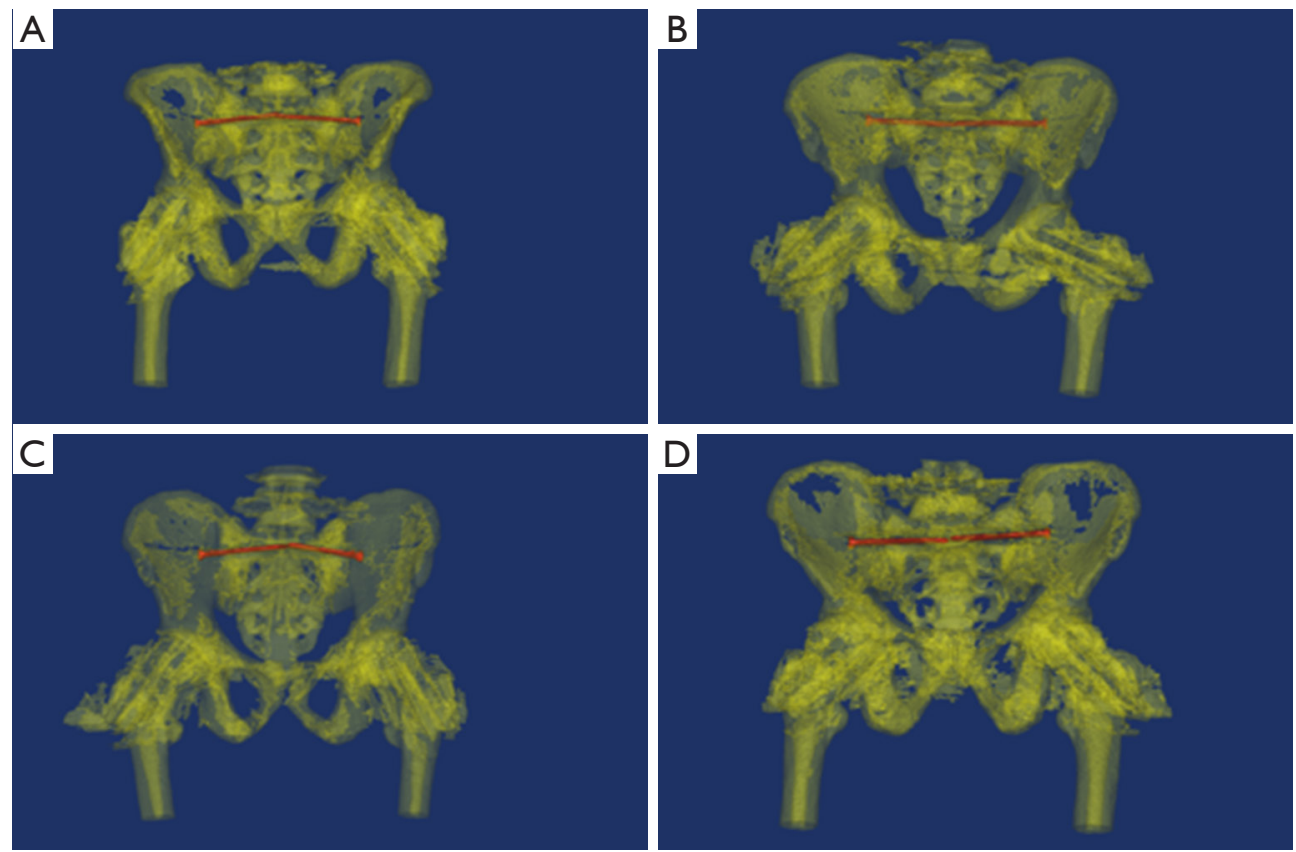

Figure 6 The effect of screw placement in specimen No. 2 (A), 3 (B), 4 (C), and 7 (D).

operative planning for sacroiliac screw placement in each case is essential for optimal results $(28,29)$.

Modern technologies such as CT scans, planar fluoroscopy, and 3D CT scans are currently used to guide the screw path. According to Zhao et al., determining the secure zone for the entry point selection of a sacroiliac screw placement based on pelvic CT scan alone is problematic due to the large surface area. It, therefore, has limited use in customizing the design for individual cases (30). Lu et al. reported that the method of obtaining a favorable entry point position and placement angle based on virtual measurement does not assure a high success rate in the absence of individualized preoperative planning (31). Moreover, planar fluoroscopy has limited application in delineating the screw placement path due to interference from anatomically contiguous structures (18). Likewise, the use of 3D CT navigation had no significant effect on the success rate of the procedure $(15,32)$. Hou et al. (33) obtained optimal screw paths by projecting the $\mathrm{S} 1$ pedicle on the sacral pedicle axis view projection as an imaging reference for sacroiliac screw fixation. However, this technique has limited applicability due to the increased sacral pedicle and inter-individual variability in sacroiliac joint anatomy, and it does not allow for the automated design of the screw path. Noser et al. and Radetzki et al. $(8,34)$ demonstrated that automated acquisition of sacroiliac screw path images was possible using thin slice pelvic CT data, using Amira software and $\mathrm{C}++$ programming. However, the technical complexity of this technique makes it challenging for orthopedic surgeons to quickly master the multiple shape simplification operations and complex programming involved, thus limiting its clinical application.

Preoperative planning combined with a thin slice CT scan confers significant advantages with simulation, such as better visualization and design of the screw path. The design of the screw path is the key link to preoperative planning for screw placement. An ideal sacroiliac screw path would be located along the long axis of the pedicle center to prevent injury to the cauda equina, sacral nerve, external and internal iliac vessels, presacral vessels, and L5/S1 intervertebral disc. Further, the screw path should traverse the auricular surface of the sacroiliac joint to improve the fixation of the pelvis. A screw path made outside the auricular surface renders the sacroiliac joint susceptible to dislocation after the insertion of the lag screw. Therefore, adhering to these criteria is important in minimizing the chance of misplacement after implantation.

The resection of the long axis of the sacral pedicle center allows for convenient translation of the screw path. Bone processes of the posterior gluteal line adjoining the origin of the screw path were subjected to $3 \mathrm{D}$ segmentation. The design of the navigation module was obtained after 
the Boolean operation [(socket module + supporting pillar) - (screw path + pelvic)] and draft. According to our experience, the bone processes of the posterior gluteal line represented the plane of optimal position, while the iliac crest was added as an assisted position plane when the posterior gluteal line was not obvious.

Sacroiliac screw placement, assisted with a 3D printing/ rapid prototyping navigation module, precludes any radiation exposure. Although planar fluoroscopy with continuous image acquisition helps in screw placement, the procedure is associated with a high degree of radiation exposure. 3D navigation affords better visualization than planar fluoroscopy; however, it still poses some radiation hazard $(4,10)$ because the surgeon's hand is exposed $(35)$. Elsewhere, the $3 \mathrm{D}$ printing/rapid prototyping navigation module has been used successfully for vertebral pedicle screw placements. Lu et al. (36) reported a $100 \%$ success rate with lumbar pedicle screw placements using reverse engineering and rapid prototyping of pedicle screws. They further confirmed the advantage of this technique for pedicle screw placements in patients with scoliosis (37). Wu et al. (38) reported an accuracy rate of $97.9 \%$ for scoliosis pedicle screw placements using rapid prototyping. In contrast, Hou et al. (33) employed a computer-assisted thermoplastic membrane navigation system for sacroiliac screw placements but reported considerable radiation exposure, which was a complicating factor. However, overall this procedure has found widespread application due to its advantages of shorter operative time, reduced blood loss, higher accuracy, and the relative ease of preoperative planning.

Compared to the percutaneous pedicle screw placement, the $3 \mathrm{D}$ printing navigation module prevents any iatrogenic injury to the superior gluteal nerve or vessels which are protected on the deep surface of the gluteus medius after blunt dissection of the gluteus maximus. Some clinical trials experimented with a modified incision, which started from the posterior superior iliac spine and proceeded $5 \mathrm{~cm}$ towards the iliac crest without turning towards the femoral greater tuberosity. With intraoperative traction, the visual field was well exposed, and the procedure was associated with less damage. Routt et al. (39) reported that placement of percutaneous pedicle screws in the sacroiliac was difficult to achieve and could cause neurovascular injury if surgeons did not understand the variability in anatomy. In their study on 58 pelvic specimens, Collinge et al. (40) reported an $18 \%$ incidence of superior gluteal neurovascular bundle damage associated with the sacroiliac screw placement.
Currently, sacroiliac screw placement based on a 3D printing navigation module is being applied in clinic settings. Other advanced techniques, including o-arm technique (41), frameless navigation (42), and micro-robots (43), are also being trialed for this purpose. Due to the relative ease of preoperative planning and the minimally invasive nature of the operation, it appears that most navigationassisted methods are appropriate for sacroiliac screw placement.

However, our study has some limitations. The technique may not be applicable in patients with severe pelvic fractures associated with fragment displacement. In such cases, any attempt at fracture reduction aided by a CT scan alone is likely to distort the shape of the pelvis. The preoperative planning of screw paths in such cases is limited due to the displaced fragments. It would also be an advantage if the design of the screw path and $3 \mathrm{D}$ navigation module were partially or automated, and further improvement is needed in methodology for this to occur. Compared to percutaneous sacroiliac screw placement, the implantation in our study induced greater blood loss and was associated with a higher rate of infection. Furthermore, the small sample size in this study limits the ability to draw firm conclusions, and these preliminary results will need to be validated in larger studies.

\section{Conclusions}

In this study, the use of the $3 \mathrm{D}$ printing navigation module allowed for optimal placement of sacroiliac screws in a large range of screw paths with relative ease. These findings are preliminary, and our results will need to be confirmed by studies with larger sample sizes before they can be applied in a real-world setting.

\section{Acknowledgments}

Funding: This study was supported by the Natural Science Foundation of Fujian Province (No. 2020J011256), the Research and Innovation Special Project of Putian University (No. 2019SZP03), and the Fujian Province Clinical Key Specialty Construction Project (No. 2018145).

\section{Footnote}

Reporting Checklist: The authors have completed the MDAR reporting checklist. Available at http://dx.doi.org/10.21037/ atm-20-7080 
Data Sharing Statement: Available at http://dx.doi. org/10.21037/atm-20-7080

Conflicts of Interest: All authors have completed the ICMJE uniform disclosure form (available at http://dx.doi. org/10.21037/atm-20-7080). The authors have no conflicts of interest to declare.

Ethical Statement: The authors are accountable for all aspects of the work in ensuring that questions related to the accuracy or integrity of any part of the work are appropriately investigated and resolved. All procedures performed in this study involving human participants were in accordance with the Declaration of Helsinki (as revised in 2013). The Institutional Review Board at the Affiliated Hospital of Putian University approved this study (batch number: 20140012). Written informed consent was obtained from all patients.

Open Access Statement: This is an Open Access article distributed in accordance with the Creative Commons Attribution-NonCommercial-NoDerivs 4.0 International License (CC BY-NC-ND 4.0), which permits the noncommercial replication and distribution of the article with the strict proviso that no changes or edits are made and the original work is properly cited (including links to both the formal publication through the relevant DOI and the license). See: https://creativecommons.org/licenses/by-nc-nd/4.0/.

\section{References}

1. Choy WS, Kim KJ, Lee SK, et al. Anterior pelvic plating and sacroiliac joint fixation in unstable pelvic ring injuries. Yonsei Med J 2012;53:422-6.

2. Sathy AK, Starr AJ, Smith WR, et al. The effect of pelvic fracture on mortality after trauma: an analysis of 63,000 trauma patients. J Bone Joint Surg Am 2009;91:2803-10.

3. Li L, Lu J, Yang L, et al. Stability evaluation of anterior external fixation in patient with unstable pelvic ring fracture: a finite element analysis. Ann Transl Med 2019;7:303.

4. Pieske O, Landersdorfer C, Trumm C, et al. CT-guided sacroiliac percutaneous screw placement in unstable posterior pelvic ring injuries: accuracy of screw position, injury reduction and complications in 71 patients with 136 screws. Injury 2015;46:333-9.

5. Sagi HC, Ordway NR, DiPasquale T. Biomechanical analysis of fixation for vertically unstable sacroiliac dislocations with iliosacral screws and symphyseal plating. J Orthop Trauma 2004;18:138-43.

6. Tile M. Pelvic ring fractures: should they be fixed? J Bone Joint Surg Br 1988;70:1-12.

7. Matta JM, Saucedo T. Internal fixation of pelvic ring fractures. Clin Orthop Relat Res 1989;(242):83-97.

8. Radetzki F, Wohlrab D, Goehre F, et al. Anatomical conditions of the posterior pelvic ring regarding bisegmental transverse sacroiliac screw fixation: a 3D morphometric study of 125 pelvic CT datasets. Arch Orthop Trauma Surg 2014;134:1115-20.

9. Korovessis P, Baikousis A, Stamatakis M, et al. Mediumand long-term results of open reduction and internal fixation for unstable pelvic ring fractures. Orthopedics 2000;23:1165-71.

10. Yinger K, Scalise J, Olson SA, et al. Biomechanical comparison of posterior pelvic ring fixation. J Orthop Trauma 2003;17:481-7.

11. Matta JM, Tornetta P 3rd. Internal fixation of unstable pelvic ring injuries. Clin Orthop Relat Res 1996:129-40.

12. Giannoudis PV, Tzioupis CC, Pape HC, et al. Percutaneous fixation of the pelvic ring: an update. J Bone Joint Surg Br 2007;89:145-54.

13. Esenkaya I. A morphologic evaluation of the sacroiliac joint and plate fixation on a pelvic model using a S1 pedicular screw, transiliosacral screws, and a compression rod for sacroiliac joint injuries. Acta Orthop Traumatol Turc 2002;36:432-41.

14. Konrad G, Zwingmann J, Kotter E, et al. Variability of the screw position after $3 \mathrm{D}$-navigated sacroiliac screw fixation. Influence of the surgeon's experience with the navigation technique. Unfallchirurg 2010;113:29-35.

15. Zwingmann J, Konrad G, Kotter E, et al. Computernavigated iliosacral screw insertion reduces malposition rate and radiation exposure. Clin Orthop Relat Res 2009;467:1833-8.

16. Hinsche AF, Giannoudis PV, Smith RM. Fluoroscopybased multiplanar image guidance for insertion of sacroiliac screws. Clin Orthop Relat Res 2002:135-44.

17. Stöckle U, König B, Hofstetter R, et al. Navigation assisted by image conversion. An experimental study on pelvic screw fixation. Unfallchirurg 2001;104:215-20.

18. Briem D, Windolf J, Rueger JM. Percutaneous, 2D-fluoroscopic navigated iliosacral screw placement in the supine position: technique, possibilities, and limits. Unfallchirurg 2007;110:393-401.

19. van Zwienen CM, van den Bosch EW, Snijders CJ, et al. Biomechanical comparison of sacroiliac screw techniques 


\section{Page 10 of 10}

for unstable pelvic ring fractures. J Orthop Trauma 2004;18:589-95.

20. Wallace TC, Blumberg JB, Johnson EJ, et al. Dietary bioactives: establishing a scientific framework for recommended intakes. Adv Nutr 2015;6:1-4.

21. Osterhoff G, Ossendorf C, Wanner GA, et al. Percutaneous iliosacral screw fixation in $\mathrm{S} 1$ and S2 for posterior pelvic ring injuries: technique and perioperative complications. Arch Orthop Trauma Surg 2011;131:809-13.

22. Iguchi T, Ogawa K, Doi T, et al. Computed tomography fluoroscopy-guided placement of iliosacral screws in patients with unstable posterior pelvic fractures. Skeletal Radiol 2010;39:701-5.

23. Ahn Y, Lee SH. Iatrogenic sacroiliac joint syndrome after percutaneous pedicle screw fixation at the L5-S1 level: case report. Neurosurgery 2010;67:E865-6; discussion E866.

24. Zheng Z, Zhang Y, Hou Z, et al. The application of a computer-assisted thermoplastic membrane navigation system in screw fixation of the sacroiliac joint--a clinical study. Injury 2012;43:495-9.

25. Marmor M, Lynch T, Matityahu A. Superior gluteal artery injury during iliosacral screw placement due to aberrant anatomy. Orthopedics 2010;33:117-20.

26. Takao M, Nishii T, Sakai T, et al. Iliosacral screw insertion using CT-3D-fluoroscopy matching navigation. Injury 2014;45:988-94.

27. Gardner MJ, Morshed S, Nork SE, et al. Quantification of the upper and second sacral segment safe zones in normal and dysmorphic sacra. J Orthop Trauma 2010;24:622-9.

28. Mendel T, Radetzki F, Wohlrab D, et al. CT-based 3 -D visualisation of secure bone corridors and optimal trajectories for sacroiliac screws. Injury 2013;44:957-63.

29. Reilly MC, Bono CM, Litkouhi B, et al. The effect of sacral fracture malreduction on the safe placement of iliosacral screws. J Orthop Trauma 2006;20:S37-43.

30. Zhao Y, Li J, Wang D, et al. Parameters of lengthened sacroiliac screw fixation: a radiological anatomy study. Eur Spine J 2012;21:1807-14.

31. Lu C, Song Y, Gao B, et al. Parameters of S1 screw fixation for percutaneous screw fixation of the sacroiliac joint using a targeting device: a digital model-based study. Nan Fang Yi Ke Da Xue Xue Bao 2014;34:869-74.

32. Arand M, Kinzl L, Gebhard F. Computer-guidance in percutaneous screw stabilization of the iliosacral joint. Clin Orthop Relat Res 2004;(422):201-7.

33. Hou Z, Zhang Q, Chen $W$, et al. The application of the axial view projection of the $\mathrm{S} 1$ pedicel for sacroiliac screw.
Chen et al. safe placement of sacroiliac screws with 3D printing

J Trauma 2010;69:122-7.

34. Noser H, Radetzki F, Stock K, et al. A method for computing general sacroiliac screw corridors based on CT scans of the pelvis. J Digit Imaging 2011;24:665-71.

35. Peng KT, Li YY, Hsu WH, et al. Intraoperative computed tomography with integrated navigation in percutaneous iliosacral screwing. Injury 2013;44:203-8.

36. Lu S, Xu YQ, Zhang YZ, et al. A novel computerassisted drill guide template for lumbar pedicle screw placement: a cadaveric and clinical study. Int J Med Robot 2009;5:184-91.

37. Lu S, Zhang YZ, Wang Z, et al. Accuracy and efficacy of thoracic pedicle screws in scoliosis with patient-specific drill template. Med Biol Eng Comput 2012;50:751-8.

38. Wu ZX, Huang LY, Sang HX, et al. Accuracy and safety assessment of pedicle screw placement using the rapid prototyping technique in severe congenital scoliosis. J Spinal Disord Tech 2011;24:444-50.

39. Routt ML Jr, Simonian PT, Mills WJ. Iliosacral screw fixation: early complications of the percutaneous technique. J Orthop Trauma 1997;11:584-9.

40. Collinge C, Coons D, Aschenbrenner J. Risks to the superior gluteal neurovascular bundle during percutaneous iliosacral screw insertion: an anatomical cadaver study. J Orthop Trauma 2005;19:96-101.

41. Silbermann J, Riese F, Allam Y, et al. Computer tomography assessment of pedicle screw placement in lumbar and sacral spine: comparison between free-hand and $\mathrm{O}$-arm based navigation techniques. Eur Spine J 2011;20:875-81.

42. Takahashi J, Hirabayashi H, Hashidate H, et al. Accuracy of multilevel registration in image-guided pedicle screw insertion for adolescent idiopathic scoliosis. Spine (Phila Pa 1976) 2010;35:347-52.

43. Togawa D, Kayanja MM, Reinhardt MK, et al. Bonemounted miniature robotic guidance for pedicle screw and translaminar facet screw placement: part 2--Evaluation of system accuracy. Neurosurgery 2007;60:ONS129-39; discussion ONS139.

(English Language Editors: D. Fitzerald and J. Chapnick)

Cite this article as: Chen X, Zheng F, Zhang G, Gao X, Wang Y, Huang W, Lin H. An experimental study on the safe placement of sacroiliac screws using a $3 \mathrm{D}$ printing navigation module. Ann Transl Med 2020;8(22):1512. doi: 10.21037/atm-207080 